\title{
Effect of Hydrogen on Blowhole Formation in Pure Iron during Solidification*
}

\author{
By Masahiro UDA, ${ }^{* *}$ Takehiro DAN ${ }^{* *}$ and Satoru OHNO**
}

\section{Synopsis}

The blowhole formation in the $\mathrm{Fe}-\mathrm{H}$ system during the period of solidification has been investigated in the present work.

Pure iron was melted by changing the partial pressure of hydrogen $\left(P_{\mathrm{H}_{2}}=0.20,0.10,0.05,0.03 ;\right.$ total pressure $\left.P_{\mathrm{H}_{2}}+P_{\mathrm{Ar}}=1 \mathrm{~atm}\right)$ and the temperature $\left(1840^{\circ}\right.$ to $\left.2510^{\circ} \mathrm{C}\right)$ with the levitation melting method, and then cast into a copper mold set on a water-cooled turntable after equilibrated with the selected atmosphere. Blowholes existing in the specimen were detected by means of specific gravity, radiographic and cross-sectional methods.

The experimental results obtained are summarized as follows:

The blowhole formation was infuenced remarkably by both the partial pressure of hydrogen and the temperature of the melt, but the results can be reduced to a very simple relation between the content of hydrogen and the presence of blowholes in the specimen. In other words the critical content of hydrogen necessary for the blowhole formation was found to be about $13 \mathrm{cc} / 100 \mathrm{~g}$ Fe.

So as to sustain a bubble in molten iron, the content of hydrogen in molten iron must be at least $25.2 \mathrm{cc} / 100 \mathrm{~g} \mathrm{Fe}$ which is the equilibrium solubility of hydrogen in molten iron at the melting point under one atmospheric pressure of hydrogen.

The critical content of hydrogen determined in the present work is much lower than this value. Accordingly, the results obtained can not easily be explained in terms of the difference between the hydrogen contents both in molten iron and in solid iron at the melting point.

If the consentration of hydrogen in front of the solidification interface is taken into account, the maximum content of hydrogen in molten iron easily exceeds the value of $25.2 \mathrm{cc} / 100 \mathrm{~g} \mathrm{Fe}$. This phenomenon was explained by the uniaxial planar solidification model: the effective distribution coefficient under these experimental conditions was estimated to be considerably higher than the equilibrium one, and the solidification distance necessary for the stable presence of a bubble in molten iron was of the order of $100 \mathrm{p}$. These estimations explain reasonably the experimental results.

Only a few blowholes were produced in pure iron specimens. But, when such a nucleation catalyst as tungsten wire or aluminum foil is added to the molten iron, many blowholes were formed in the specimen melted under the same experimental conditions. These results may be due to the suppression of the heterogeneous nucleation for the bubble formation because of the cleanliness of pure iron melted in this work and to the promotion of the heterogeneous nucleation because of the presence of a nucleation catalyst.

\section{Introduction}

It is well known that the dissolved hydrogen in iron and steel brings about undesirable phenomena such as flakes, hydrogen embrittlement and delayed failure. Moreover, the decrease in the solubility of hydrogen on the period of solidification can produce blowholes in castings and welds.

In direct connection with the soundness of steel ingots, many works have been made on the blowholes caused by hydrogen. Sykes, et $a l .{ }^{11}$ suggested that the molten steel with the hydrogen content of 8 to
$12 \mathrm{cc} / 100 \mathrm{~g} \mathrm{Fe}$ becomes "wild" in the case of high alloy steels melted in an electric furnace. Barraclough $^{2)}$ investigated various killed steels melted in a basic electric furnace and found that the ingot becomes "porous" when the content of hydrogen in molten steel such as carbon steels and low alloy steels exceeds 6.5 to $7.0 \mathrm{cc} / 100 \mathrm{~g} \mathrm{Fe}$, but it becomes "wild" if the content of hydrogen exceeds 8.5 to $9.0 \mathrm{cc} / 100 \mathrm{~g} \mathrm{Fe}$.

On the other hand, the problem of hydrogen is also discussed in the field of welding. In this field, the arc is generally used as a heat source. At high temperatures $\left(6000^{\circ}\right.$ to $\left.10000^{\circ} \mathrm{K}\right)$ of an arc column, gas molecules are probably dissociated into atoms or ions. It was found by the authors that the gas content in metals amounts to several times of the equilibrium solubility of gas species under certain combinations of metal and gas. ${ }^{3,4)}$ Thus, blowholes are apt to be readily formed inside of the welded metal. From this reason many works have been made on the blowholes in the welded metals. It is usually recognized that blowholes due to hydrogen in the welded metal are produced by organic matter, absorbed moisture and crystal water in flux materials of welding rod, oil on the surface of welding materials, or moisture in shielded gases. ${ }^{51}$ Masumoto $^{6}$ ) reported that on the gas-shielded welding, the formation of blowholes in the welded mild steel starts to occur at $10 \% \mathrm{H}_{2}$ in the $\mathrm{CO}_{2}-\mathrm{H}_{2}$ atmosphere and at $4.8 \% \mathrm{H}_{2}$ in the $\mathrm{Ar}-\mathrm{H}_{2}$ atmosphere.

As mentioned above, the formation of blowholes by hydrogen in iron and steel is considerably well studied by many investigators. But there are only a few fundamental works concerning the mechanism of blowhole formation.

Metal-gas reactions in both non-arc and arc melting have been investigated and the work for the $\mathrm{Al}$ $\mathrm{H}$ system with regard to the blowhole formation has already been reported by the authors. ${ }^{7,8)}$ This work was undertaken to clarify the mechanism of the blowhole formation in the $\mathrm{Fe}-\mathrm{H}$ system from the viewpoint of chemical metallurgy.

\section{Experimental Methods}

Pure iron was melted at various temperatures under various partial pressures of hydrogen at one atmospheric pressure in total with a levitation melting apparatus. In order to equilibrate sufficiently the molten iron with the atmosphere, the melting was 
made for 2 min after the specimen was heated to a constant temperature. The molten iron was cast into the copper mold which was placed on a water-cooled turntable. Then the blowholes existing in the cast specimen were observed.

As to the melting time, one of the authors confirmed that the equilibrium between iron and nitrogen was attained within $100 \mathrm{sec}$ after the melt was heated to a constant temperature from the experiment on the solubility of nitrogen in pure iron made by using the levitation melting method. In view of the diffusion coefficient of hydrogen which is higher than that of nitrogen in molten iron, it is reasonable to estimate that the equilibrium between iron and hydrogen can be attained within 2 min. ${ }^{9-11)}$

\section{Materials}

Electrolytic iron (99.97\% in purity) was melted with a vacuum induction furnace $\left(10^{-3}\right.$ to $10^{-4}$ Torr). The vacuum remelted iron was hot-rolled into a rod of 10 or $16 \mathrm{~mm} \phi$ and lathed to remove the oxide film, and cut to a cylindrical piece of 7 to $10 \mathrm{~mm}$ diameter and 5 to $10 \mathrm{~mm}$ long which is weighing from 3 to $6 \mathrm{~g}$. The experimental temperature was changed by the proper selection of the weight of specimen, gas atmosphere and coil geometry. Table 1 shows the chemical composition of electrolytic iron used in this experiment.

\section{Experimental Apparatus}

The levitation melting apparatus made by Kokusai Electric Co., Type NT-1511A having the maximum output $15 \mathrm{~kW}$ and the frequency of current $400 \mathrm{kHz}$ was used in the current work and is schematically shown in Fig. 1. A levitation coil is set at the central part of the melting chamber. Copper molds can be respectively mounted just below the coil by turning the table. This turntable is cooled by water in order to prevent the preheating of molds by the electric current induced and to keep at a constant condition during the casting of molten iron. Six specimens can be melted successively without breaking the atmosphere of the chamber. The chamber was evacuated to about $10^{-2}$ Torr and a defined $\mathrm{Ar}-\mathrm{H}_{2}$ gaseous mixture was introduced into the chamber up to one atmospheric pressure.

The size of copper mold used in this work is $10 \mathrm{~mm}$ inner diameter and $20 \mathrm{~mm}$ outer diameter. The inside wall is tapered in order to take out the specimen smoothly. Figure 2 shows the cooling curve of a specimen. Temperature of the specimen was measured with a Two Color Eye Type Pyrometer (made by Shiguma Electronics Industry Co.) sighted through a prism onto the surface of the levitated droplet.

Table 1. Chemical composition of electrolytic iron

\begin{tabular}{c|ccccccc} 
Element & $\mathrm{C}$ & $\mathrm{Si}$ & $\mathrm{Mn}$ & $\mathrm{P}$ & $\mathrm{S}$ & $\mathrm{Cu}$ & $\mathrm{O}$ \\
\hline wt $\%$ & 0.005 & 0.005 & 0.006 & 0.004 & 0.004 & 0.004 & 0.077
\end{tabular}

\section{Experimental Conditions}

The experimental conditions adopted for the present work are listed in Table 2.

\section{Methods Used for the Observation of Blowholes}

The inspection of blowholes existing in the solidified specimen was made by use of the following methods :

1) The specific gravity measurement

2) The radiographs

3) The observation of cross-section.

The first method is useful to estimate quantitatively

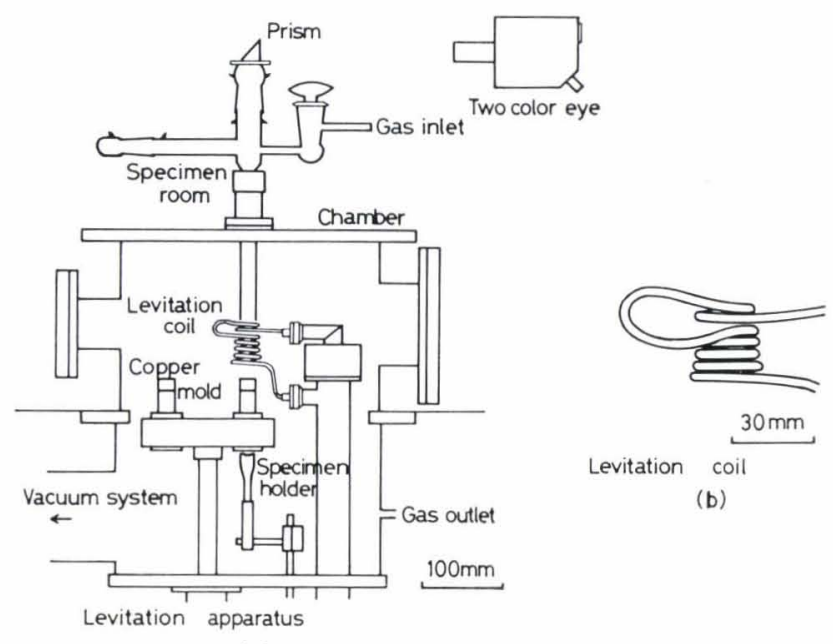

(a)

Fig. 1. Schematic diagram of levitation apparatus and shape of levitation coil

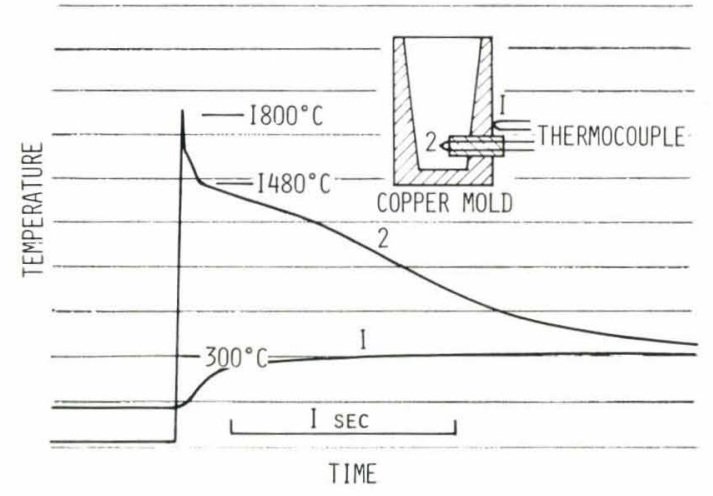

Fig. 2. Cooling curve of specimen

Table 2. Experimental conditions

\begin{tabular}{cc} 
Sample & Pure iron $(99.97 \%)$ \\
\hline Atmosphere & $20 \% \mathrm{H}_{2}-\mathrm{Ar}\left(1865^{\circ} \sim 2120^{\circ} \mathrm{C}\right)$ \\
and & $10 \% \mathrm{H}_{2}-\mathrm{Ar}\left(1840^{\circ} \sim 2350^{\circ} \mathrm{C}\right)$ \\
temperature & $5 \% \mathrm{H}_{2}-\mathrm{Ar}\left(1950^{\circ} \sim 2510^{\circ} \mathrm{C}\right)$ \\
& $3 \% \mathrm{H}_{2}-\mathrm{Ar}\left(2100^{\circ} \sim 2500^{\circ} \mathrm{C}\right)$ \\
Atmospheric pressure & 1 atm \\
\hline Melting time & $120 \mathrm{sec}($ at a constant temperature $)$ \\
Gas flow rate & $5 \mathrm{l} / \mathrm{min}$
\end{tabular}



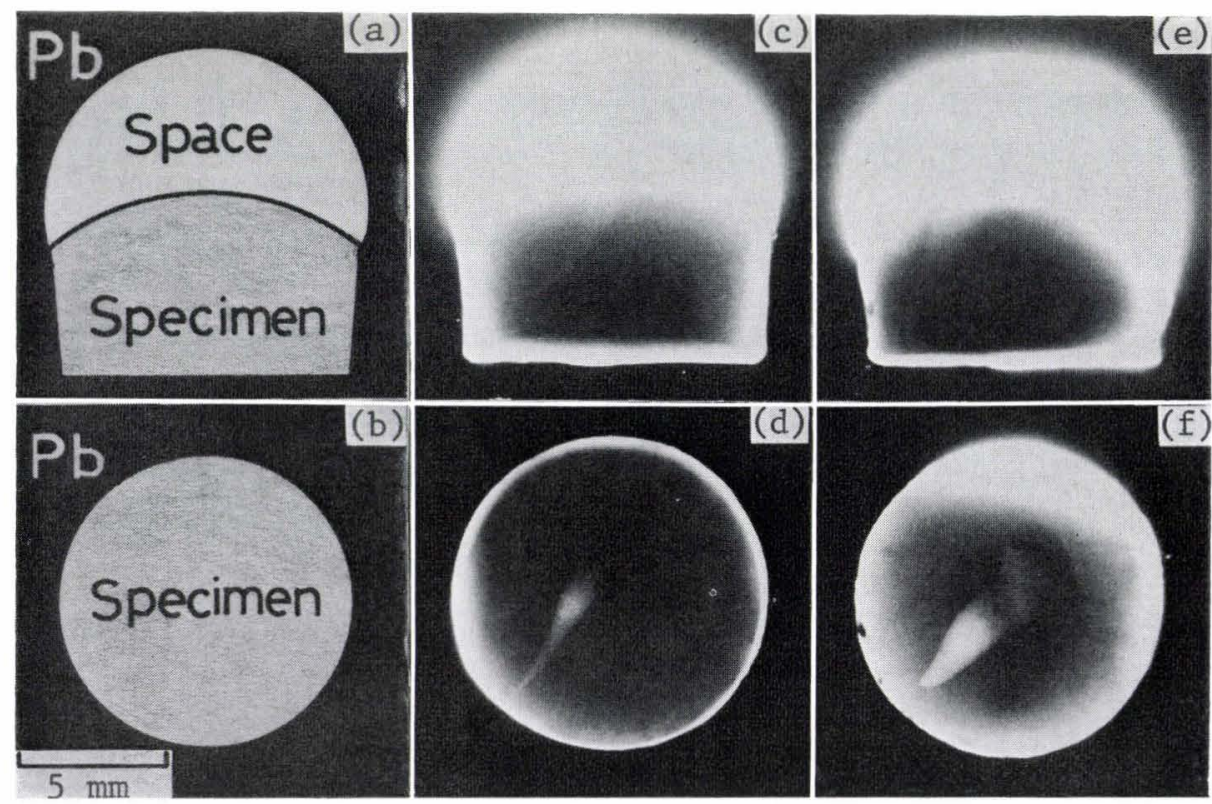
(a), (b)
Schematic figures
Atmosphere
(c), (d)
$10 \% \mathrm{H}_{2}-\mathrm{Ar}$
$20{ }_{0} \mathrm{H}_{2}-\mathrm{Ar}$
Flow rate
$5 l / \mathrm{min}$
$5 \mathrm{l} / \mathrm{min}$
Melt temperature
$2050^{\circ} \mathrm{C}$
$1950^{\circ} \mathrm{C}$
Specimen weight
$4.5 \mathrm{~g}$
$3.5 \mathrm{~g}$

Porosity

\section{(a), (c), (e) Side views \\ (b), (d), (f) Plane figures}

Photo. 1. Radiographs of typical specimens

the amount of blowholes existing in the specimen. On the other hand, radiographs, together with the third method, are very effective for the observation of an originated point and a shape of blowhole. In order to obtain accurate informations, a few radiographs were taken from various directions of the specimen. It should be noted that the smaller blowhole than the smallest indication of a penetrator can not be detected even by the radiography. Radiographs were taken with an ISOVOLT 150 type radiographic testing apparatus (made by Rich. Seifert \& Co.) according to the JIS Z 3104 (Japan Industrial Standard: "Methods of Radiographic Test and Classification of Radiographs for Steel Welds"). The tube voltage was $100 \mathrm{kVp}$, the tube current $8 \mathrm{~mA}$, and the exposure time 2 to $2.5 \mathrm{~min}$. The specimen was surrounded with a $2 \mathrm{~mm}$ thick $\mathrm{Pb}$ plate. Ultrafine and high contrast X-ray films were used. An attention was paid to the selection of a cross-section of the specimen, because proper informations were hardly obtained if unsuitable one was selected. The results of radiographs sufficiently referred to the selection of the cross-section.

As described above, these methods have both merits and demerits, respectively. Accordingly careful considerations should be given for the evaluation of the results obtained by these methods.

\section{Experimental Results}

Typical radiographs of solidified specimens are shown in Photo. 1. As shown in the left schematic figures, the circumferential dark parts of these radio-

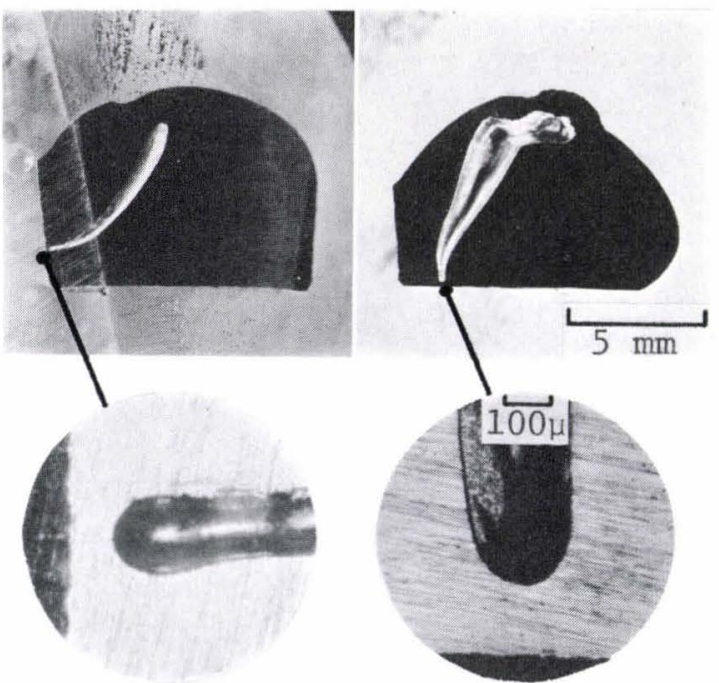

Photo. 2. Photographs of the cross-section of typical specimens. The upper photographs show the cross-sections of the same specimens that in Photo. 1. The lower ones are the microscopic photographs which show the place of blowhole origin in those specimens.

graphs are corresponding to the shadow of the lead plate for the screening of the X-ray and the inside parts are corresponding to the specimen itself. The upper blank parts of the side view correspond to the space between the specimen and the covering lead plate. The cross-sectional photographs of the same specimens shown in Photo. 1 are given in Photo. 2. Shapes of the blowholes are well compared with each other. 
Photographs 1 and 2 show that the originated points of blowholes are very close to the wall of solidified specimens. According to the microscopic photographs given in Photo. 2, the distance from the wall surface of the specimen to the originated point of blowhole is about 100 to $150 \mu$. The number of blowholes existing in the specimen melted at comparatively low temperature (about $2000^{\circ} \mathrm{C}$ ) is at most two or three. From the typical macrostructure of the solidified specimen shown in Photo. 3, it is obvious that the blowholes grow up conically along the solidified structure. Thus, it seems that the growth rate of blowhole is almost comparable to the solidification rate of the specimen.

As described above, the characteristics of blowholes found in the $\mathrm{Fe}-\mathrm{H}$ system are in contrast with those in the $\mathrm{Al}-\mathrm{H}$ system. ${ }^{7)}$ In the latter system, a lot of spherical blowholes were present uniformly over the whole specimen.

As shown in Photos. 1 and 2, the top angle of conical blowhole depends on the partial pressure of hydrogen in the melting atmosphere. The top angle of blowhole found in the specimen melted under a $10 \% \mathrm{H}_{2}-\mathrm{Ar}$ atmosphere is smaller than that in the specimen melted under a $20 \% \mathrm{H}_{2}-\mathrm{Ar}$ atmosphere. As the latter has a higher hydrogen content than the former, the growth rate of blowhole in the latter may be faster than that in the former.

Experimental results are summarized in Table 3. As shown in this table, the critical temperature for blowhole formation decreases with increasing partial pressure of hydrogen in the atmosphere. The porosity of the specimen also seems to increase with increasing content of hydrogen, but it shows some scatter. The scatter indicates that the blowhole formation depends remarkably on the presence of non-metallic inclusions which facilitate the heterogeneous nucleation of blowhole.

As already described in the preceding paragraph, only two or three blowholes are produced in the pure iron specimen because of the cleanliness of the material. Accordingly, the following three experiments were also undertaken in order to facilitate the heterogeneous nucleation of blowhole.

\section{Tungsten Wire}

Molten iron was cast into the copper mold in which a piece of tungsten wire was set. The solid surface of tungsten wire may facilitate the heterogeneous nucleation of blowhole. The results of this experiment are given in Photo. 4 and Table 3. Photograph 4 shows the radiographs and the cross-sectional photographs of the specimens which were melted under a $20 \% \mathrm{H}_{2}-\mathrm{Ar}$ atmosphere at $2100^{\circ}$ and $2040^{\circ} \mathrm{C}$. As is obvious from Photo. 4, a number of blowholes were observed in the specimens. Table 3 also shows that these specimens are very porous and their porosities attain to nearly $40 \mathrm{vol}^{\%}$ or higher.

These results differ considerably from those for pure iron melted (without tungsten wire) under the same experimental conditions. As the tungsten wire facilitates remarkably the heterogeneous nucleation

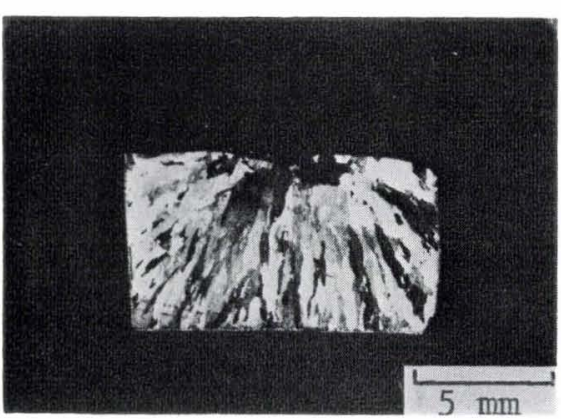

Photo. 3. Macrostructure of typical specimen. This specimen is pure iron which was melted in $10 \% \mathrm{H}_{2}-\mathrm{Ar}$ atmosphere at $2110^{\circ} \mathrm{C}$.
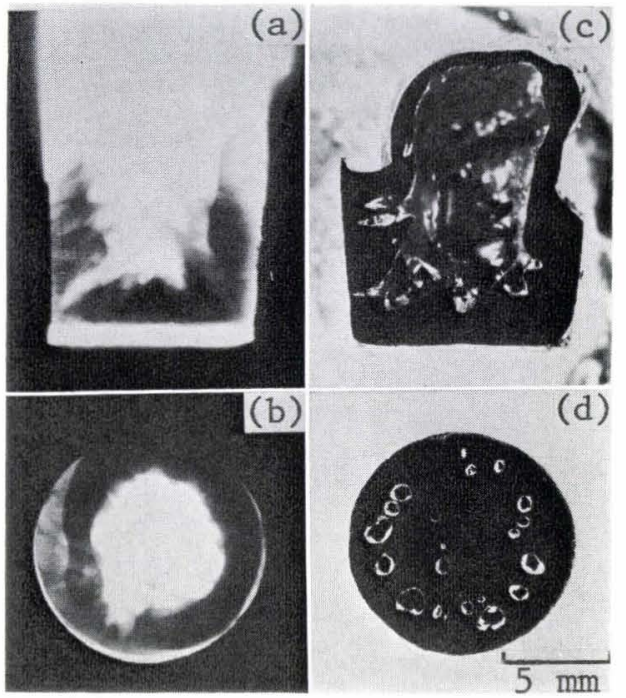

(d)

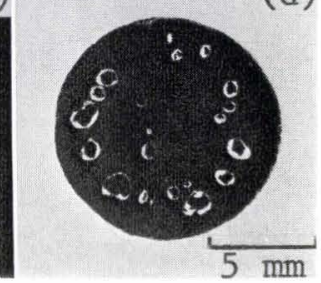

(a), (b) Radiographs

(c), (d) Cross-sectional photographs

(a), (c) Side views (Atmosphere: $20_{0}^{\circ} \mathrm{H}_{2}-\mathrm{Ar}$, Flow rate: $5 \mathrm{l} / \mathrm{min}$, Melt temperature: $2100 \mathrm{C}$, Specimen weight: $5.1 \mathrm{~g}$, Porosity: $37.8 \mathrm{vol}$ o)

(b), (d) Plane figures (Atmosphere: $20 \% \mathrm{H}_{2}-\mathrm{Ar}$, Flow rate: $5 / \mathrm{min}$, Melt temperature: $2040 \mathrm{C}$, Specimen weight: $5.0 \mathrm{~g}$, Porosity: $40.7 \mathrm{vol}^{\circ}$ )

Photo. 4. Shape of blowholes in the specimens cast into the copper mold in which $50 \mu$ tungsten wire is set

of blowhole, blowholes are easily formed in pure iron even under the condition of supersaturated hydrogen by which blowholes are hardly produced.

As shown in Table 3, the porosities of the specimens melted under a $10 \% \mathrm{H}_{2}-\mathrm{Ar}$ atmosphere are $0 \mathrm{vol}^{\%}$. This value suggests that no hydrogen supersaturates in the specimen under these melting conditions. Thus, no matter how a tungsten wire facilitates the heterogeneous nucleation of blowhole, blowholes are not formed in the specimen.

\section{Deoxidation Product $\mathrm{Al}_{2} \mathrm{O}_{3}$}

Dissolved oxygen in pure iron is deoxidized by aluminum inserted as a foil into the specimen. In this case, deoxidation product, $\mathrm{Al}_{2} \mathrm{O}_{3}$, may facilitate the heterogeneous nucleation of blowhole. The re- 
Table 3. Summary of experimental results

\begin{tabular}{|c|c|c|c|c|c|c|c|c|c|c|c|c|}
\hline & \multicolumn{3}{|c|}{$3 \% \mathrm{H}_{2}-\mathrm{Ar}$} & \multicolumn{3}{|c|}{$5 \% \mathrm{H}_{2}-\mathrm{Ar}$} & \multicolumn{3}{|c|}{$10 \% \mathrm{H}_{2}-\mathrm{Ar}$} & \multicolumn{3}{|c|}{$20 \% \mathrm{H}_{2}-\mathrm{Ar}$} \\
\hline & $\begin{array}{l}\text { Weight } \\
\text { (g) }\end{array}$ & $\begin{array}{l}\text { Temp. } \\
\left({ }^{\circ} \mathrm{C}\right)\end{array}$ & $\begin{array}{l}\text { Porosity } \\
\text { (vol\%) }\end{array}$ & $\begin{array}{c}\text { Weight } \\
\text { (g) }\end{array}$ & $\begin{array}{l}\text { Temp. } \\
\left({ }^{\circ} \mathrm{C}\right)\end{array}$ & $\begin{array}{l}\text { Porosity } \\
\text { (vol \%) }\end{array}$ & $\begin{array}{l}\text { Weight } \\
\text { (g) }\end{array}$ & $\begin{array}{l}\text { Temp. } \\
\left({ }^{\circ} \mathrm{C}\right)\end{array}$ & $\begin{array}{l}\text { Porosity } \\
(\text { vol \%) }\end{array}$ & $\begin{array}{l}\text { Weight } \\
\text { (g) }\end{array}$ & $\begin{array}{l}\text { Temp. } \\
\left({ }^{\circ} \mathrm{C}\right)\end{array}$ & $\begin{array}{l}\text { Porosity } \\
\text { (vol \%) }\end{array}$ \\
\hline \multirow{18}{*}{ Pure iron } & & & & & & & 1.3 & 1840 & 0 & & & \\
\hline & & & & & & & 1.4 & 1840 & 0 & & & \\
\hline & & & & & & & 2.5 & 1915 & 0 & 2.5 & 1865 & 0.91 \\
\hline & & & & & & & 3.2 & 1940 & 0 & 3.4 & 1940 & 2.22 \\
\hline & & & & & & & 3.5 & 1980 & 0 & 3.6 & 1950 & 2.37 \\
\hline & & & & 1.2 & 1950 & 0 & 3.7 & - & 0 & 3.6 & 1965 & 10.1 \\
\hline & & & & 1.6 & 1980 & 0 & 3.9 & 2065 & 1.14 & 3.7 & 1920 & 2.60 \\
\hline & - & 2100 & 0 & 2.1 & 2010 & 0 & 4.1 & 2110 & 0 & 4.0 & 1960 & 6.30 \\
\hline & 8.2 & 2425 & 0 & $* 4.0$ & 2040 & 0 & 4.2 & - & 0 & 4.5 & - & 1.01 \\
\hline & - & 2500 & 0 & $* 4.3$ & 2150 & 0 & 4.2 & 2000 & 0 & 4.5 & 1990 & 0 \\
\hline & & & & 7.1 & 2360 & 0.05 & 4.5 & 2050 & 0.36 & 4.6 & 1960 & 0 \\
\hline & & & & $* 7.4$ & 2330 & 0 & 4.5 & 2050 & 1.58 & 5.0 & 2050 & 20.6 \\
\hline & & & & 11.0 & 2510 & 41.1 & 4.7 & 2107 & 0 & 5.3 & 2000 & 13.8 \\
\hline & & & & & & & 5.3 & 2140 & 10.2 & 6.0 & 2105 & 12.9 \\
\hline & & & & & & & 5.8 & 2140 & 2.59 & 6.3 & 2120 & 21.7 \\
\hline & & & & & & & 5.9 & 2160 & 16.1 & & & \\
\hline & & & & & & & $* 6.6$ & 2280 & 15.2 & & & \\
\hline & & & & & & & 8.0 & 2350 & 10.0 & & & \\
\hline \multirow{5}{*}{$\begin{array}{c}\text { Pure iron } \\
(50 \mu \phi \mathrm{W} \text { wire } \\
\text { inserted }\end{array}$} & & & & & & & & & & 5.0 & 2040 & 40.7 \\
\hline & & & & & & & 3.8 & 2025 & 0 & 5.0 & 2040 & 41.7 \\
\hline & & & & & & & 3.9 & 2020 & 0 & 5.1 & 2100 & 37.8 \\
\hline & & & & & & & 3.9 & 2030 & 0 & 5.5 & - & 35.9 \\
\hline & & & & & & & 4.2 & 2030 & 0 & 5.7 & 2120 & 24.6 \\
\hline \multirow{6}{*}{$\begin{array}{l}\text { Pure iron } \\
\text { (Al inserted) }\end{array}$} & & & & & & & 3.8 & 1965 & 0 & 5.0 & 1950 & 13.6 \\
\hline & & & & & & & 3.8 & 2020 & 1.17 & 5.1 & 2060 & 14.5 \\
\hline & & & & & & & 3.8 & 1885 & 0 & 5.4 & 2050 & 13.3 \\
\hline & & & & & & & 3.8 & 1980 & 0 & 5.5 & 2070 & 17.2 \\
\hline & & & & & & & 3.9 & 2010 & 0 & 5.9 & 2050 & 20.7 \\
\hline & & & & & & & 5.4 & 2030 & 0 & & & \\
\hline \multirow{5}{*}{ Cast iron } & & & & & & & & & & 4.8 & 2000 & 44.5 \\
\hline & 4.8 & 2030 & 0 & & & & 6.5 & 2080 & 0.33 & 5.4 & 2030 & 32.4 \\
\hline & 5.2 & 2040 & 0 & & & & 6.6 & 2080 & 1.59 & 5.7 & 2035 & 40.3 \\
\hline & 5.2 & 2040 & 0 & & & & 7.8 & 2120 & 0 & 5.8 & 2040 & 40.6 \\
\hline & 5.7 & 2065 & 0 & & & & & & & 6.1 & 1995 & 38.4 \\
\hline
\end{tabular}

no marks: Gas flow rate $5 \mathrm{l} / \mathrm{min}$, melting time $120 \mathrm{sec}$

* Gas flow rate $1 \mathrm{l} / \mathrm{min}$, melting time $60 \mathrm{sec}$

- Not determined

sults of this experiment are given in Photo. 5 and Table 3. Photograph 5 shows the radiographs and the cross-sectional photographs of the specimen melted under a $20 \% \mathrm{H}_{2}-\mathrm{Ar}$ atmosphere at $2070^{\circ} \mathrm{C}$. Numerous blowholes are observed inside of the specimen and the porosity attains to 13.2 to $17.2 \mathrm{vol} \%$. In this case, however, the formation of blowhole is not so vigorous as in the former case 1 . Since the specific gravity of $\mathrm{Al}_{2} \mathrm{O}_{3}$ is much smaller than that of molten iron, the deoxidation product, $\mathrm{Al}_{2} \mathrm{O}_{3}$, floats to the surface of molten iron during the periods of melting and solidification. From this reason, perfect contributions of $\mathrm{Al}_{2} \mathrm{O}_{3}$ are hardly expected for the nucleation of blowhole.

\section{The First Crystal " Cementite "}

In the first place, cementite is crystallized out of the molten hyper-eutectic cast iron during the period of solidification. Accordingly, it seems that the first crystal gives sites for the nucleation of blowhole, and the similar results to the cases 1 and 2 are anticipated. The results obtained are given in Photo. 6 and Table 3. Photograph 6 shows the radiographs and the cross-sectional photographs of the specimens melted under a $20 \% \mathrm{H}_{2}-\mathrm{Ar}$ atmosphere at $2000^{\circ}$ and $2030^{\circ} \mathrm{C}$. As is obvious from Table 3, the porosities of the specimens are much larger than those of the specimens melted under a $10 \% \mathrm{H}_{2}-\mathrm{Ar}$ atmosphere.

These results closely resemble those of the cases 1 

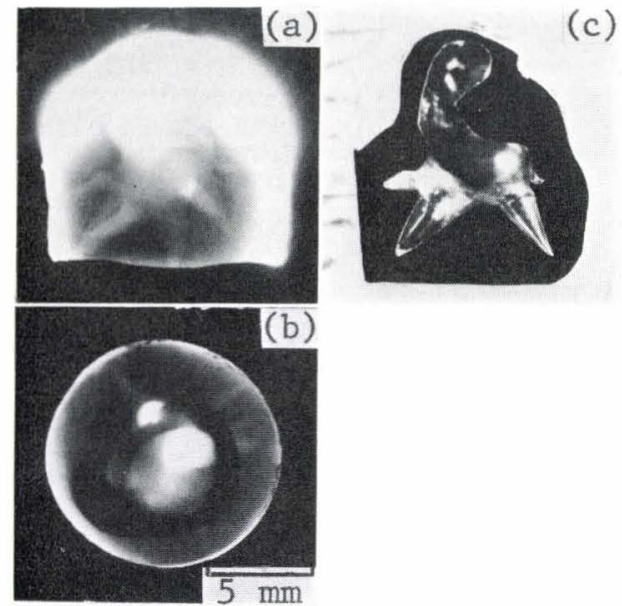

(a), (b) Radiographs

(c) Cross-sectional photograph

(a), (c) Side views

(b) Plane figure

Photo. 5. Shape of blowholes in the specimen in which $\mathrm{Al}_{2} \mathrm{O}_{3}$ is formed by the addition of aluminum (Atmosphere: $20 \% \mathrm{H}_{2}-\mathrm{Ar}$, Flow rate: $5 \mathrm{l} / \mathrm{min}$, Melt temperature: $2070 \mathrm{C}$, Specimen weight: $5.5 \mathrm{~g}$, Porosity: 17.2 $\operatorname{vol}^{\circ} \%$ )

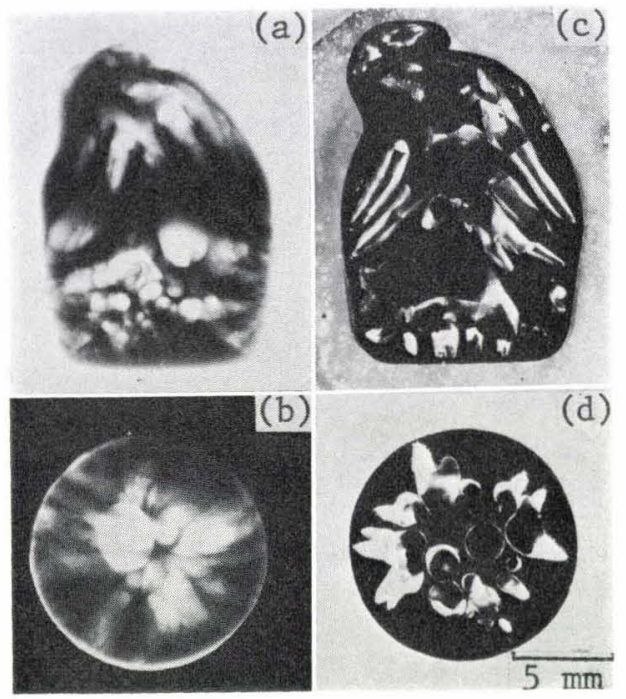

(a), (b) Radiographs

(c), (d) Cross-sectional photographs

(a), (c) Side views (Atmosphere: $20 \% \mathrm{H}_{2}-\mathrm{Ar}$, Flow rate: $5 \mathrm{l} / \mathrm{min}$, Melt temperature: $2000^{\circ} \mathrm{C}$, Specimen weight: $4.8 \mathrm{~g}$, Porosity: 44.5 $\mathrm{vol}^{\%}$ )

(b), (d) Plane figure (Atmosphere: $20 \% \mathrm{H}_{2}-\mathrm{Ar}$, Flow rate: $5 \mathrm{l} / \mathrm{min}$, Melt temperature: $2030^{\circ} \mathrm{C}$, Specimen weight: $5.4 \mathrm{~g}$, Porosity: $32.4 \mathrm{vol}^{\%}$ )

Photo. 6. Shape of blowholes in the hyper-eutectic cast iron specimens

and 2. It seems that the first crystal "cementite" facilitates the heterogeneous nucleation of blowhole. But these results could not directly be compared with those of pure iron (without tungsten wire), because the solubility of hydrogen in cast iron containing $4.28 \%$ carbon and $0.8 \%$ silicon differs markedly from that of pure iron.

The above results, however, show that when pure

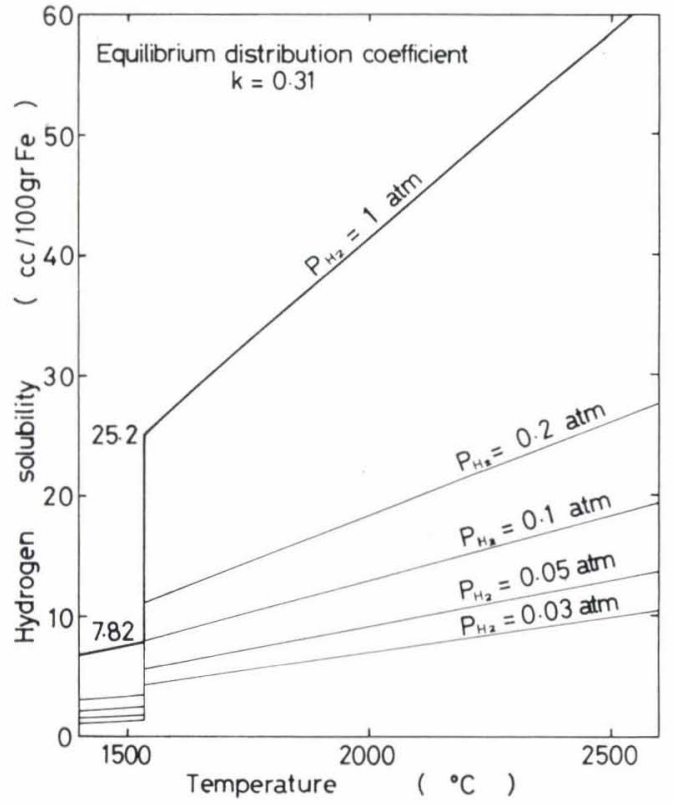

Fig. 3. PCT-diagram of the Fe-H system. Curves for various hydrogen partial pressures are calculated by means of Sieverts' law

iron is very clean, blowholes are hardly formed because of the insufficient nucleation, even though the amount of dissolved hydrogen in the specimen is satisfactory for the blowhole formation, and that the non-metallic inclusions facilitate the heterogeneous nucleation of blowhole.

\section{Discussions}

The solubility of hydrogen in pure iron has been determined by many investigators. The PCT-diagram of the $\mathrm{Fe}-\mathrm{H}$ system is shown in Fig. 3. The solubility data in this figure are based on the experiments made by Weinstein and Elliott ${ }^{12}$ for molten iron and by Geller and Tak-Ho Sun ${ }^{13)}$ for $\delta$-iron. Figure 3 also shows the equilibrium solubilities of hydrogen at various hydrogen partial pressures which were calculated on the basis of Sieverts' law.

The equilibrium distribution coefficient, $k$, during the period of solidification is given by the ratio of the solubility of hydrogen in the solid phase, $7.82 \mathrm{cc} /$ $100 \mathrm{~g} \mathrm{Fe}$ to that in the liquid phase, $25.2 \mathrm{cc} / 100 \mathrm{~g} \mathrm{Fe}$. The equilibrium distribution coefficient of the $\mathrm{Fe}-\mathrm{H}$ system is 0.31 . In a practical solidification process a distribution coefficient is not equal to the equilibrium value, but to an effective one which depends generally on the rate of solidification. It is very interesting to know the effective distribution coefficient in this experiment. This problem will be discussed in the later paragraph.

The experimental results obtained are plotted in Fig. 4. The content of dissolved hydrogen in the specimen is calculated on the basis of Sieverts' law. As is obvious from this figure, the degree of blowhole formation depends remarkably on both the temperature of the melt and the partial pressure of hydrogen in the atmosphere. But, there is a definite critical content of hydrogen in the specimen for the blow- 


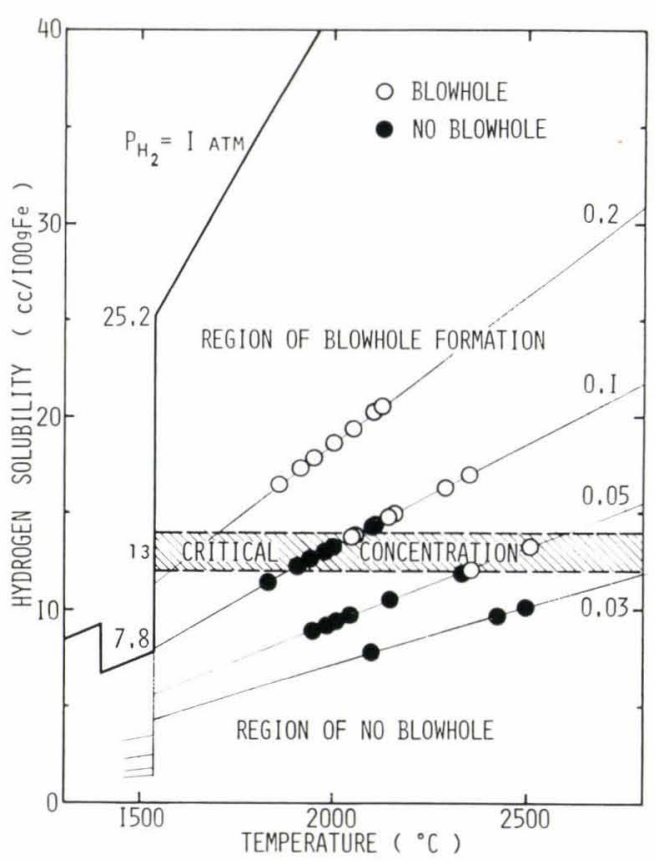

Fig. 4. Relationship between the PCT curve of hydrogen in pure iron and blowhole formation in specimens (Total pressure $1 \mathrm{~atm}$ )

hole formation. This value is about $13 \mathrm{cc} / 100 \mathrm{~g} \mathrm{Fe}$ under these experimental conditions.

Now, let us assume that a spherical bubble is present in molten iron. The condition ${ }^{14}$ under which this bubble is sustained in molten iron can be expressed as follows:

$$
P \geqq P_{B}+\rho g h+2 \gamma / r
$$

where, $P:$ the internal pressure of this bubble

$P_{B}$ : the external pressure over the surface of molten iron

$h$ : the distance from the surface of molten iron to the center of this bubble

$r$ : the radius of this bubble

$g$ : the gravity constant

$\mu$ and $\gamma$ : the density and the surface tension of molten iron, respectively.

The second and third terms on the right-hand side of Eq. (1) are ascribed to the static pressure and the surface tension of molten iron, respectively. The order of each term on Eq. (1) is estimated as follows: $P_{B}$ is equal to one atmospheric pressure under the conditions of this experiment, $h$ is the height of specimen (about $1 \mathrm{~cm}$ ) and $r$ is about $85 \mu$, which is estimated from the radii of blowholes at the originated point shown in the microscopic photographs of Photo. 2. The density and the surface tension of molten iron are $7.02 \mathrm{~g} / \mathrm{cm}^{3} \quad\left(1550^{\circ} \mathrm{G}\right)^{15)}$ and $1700 \mathrm{dyn} / \mathrm{cm}$ $\left(1539^{\circ} \mathrm{C}\right),{ }^{16}$ respectively. These values are substituted into Eq. (1). Each term is estimated in terms of the atmospheric pressure unit. The first term is equal to 1 , the second one 0.01 , and the third one 0.39. It was found that the first term contributes largely to the internal pressure of this bubble.

In this case, the radius of bubble, $r$, is estimated from the blowhole existing in the solidified specimens.

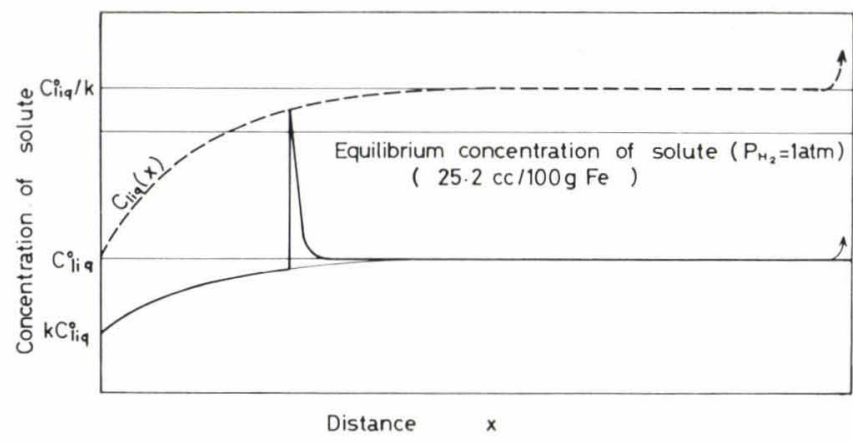

Fig. 5. Solute distribution during uniaxial solidification

The radius of a bubble embryo may be smaller than the estimated value. Therefore, the estimated value of the third term may be smaller than the real value. In the practical process, however, blowholes can be produced under a considerably low pressure due to the heterogeneous nucleation. It is difficult to estimate which of these factors contributes to the origination of blowhole in the present work. In view of the experimental results described in the third chapter, it seems that the latter effect gives a largest contribution to the process of blowhole formation. Therefore, the effect of the third term on the internal pressure, $P$, was neglected in the following discussion. Equation (1) is simplified on the basis of this assumption:

$$
P \geqq P_{B} \quad(=1 \mathrm{~atm}) .
$$

It is assumed that the gas existing in the bubble is only hydrogen. The content of hydrogen dissolved in the sample with which a bubble is surrounded should be equal to the equilibrium solubility of hydrogen. Under the experimental conditions adopted, this value is cqual to $25.2 \mathrm{cc} / 100 \mathrm{~g} \mathrm{Fe}$. As is obvious from Fig. 4, the results obtained from this experiment show that the critical content of dissolved hydrogen in molten iron for blowhole formation is $13 \mathrm{cc} / 100 \mathrm{~g} \mathrm{Fe}$. These results are contradictory to the condition mentioned above.

Therefore, the concentration of a solute in front of the solidification interface during the period of solidification must be considered. Even if the content of dissolved hydrogen in the bulk of molten iron is low, hydrogen may be concentrated in the front region of the solidification interface. It is assumed that the rate of solidification is constant and is very rapid, the diffusion of a solute in the solid phase is negligibly small, no stirring takes place in the liquid phase, the transference of the solute in the liquid phase is ascribed only to the diffusion, and the distribution coefficient of the solute is kept constant during the period of solidification. Such an uniaxial planar solidification process is schematically shown in Fig. $5 .{ }^{17,18)}$ In practice, the solidification proceeds threedemensionally and both the rate of solidification and the effective distribution coefficient vary with the progress of solidification. Accordingly, the type of solidification process varys with the change of these factors. For elucidation of blowhole formation, the 
above simple model is applied in the first place.

In Fig. 5, the horizontal and vertical axes represent the direction of solidification and the content of a solute, respectively. When the initial content of the solute is defined as $C_{\text {liq }}^{\circ}$, the content of the solute in the first solid phase is equal to $k C_{1 \mathrm{iq}}^{\circ}$ at the starting point of the solidification $x=0$. When $k$ is smaller than unity (for the $\mathrm{Fe}-\mathrm{H}$ system, $k$ is equal to 0.31 as described previously), the solute is rejected from the solid phase to the liquid one which is located in front of the solidification interface. As the rate of solidification is faster than the diffusion rate of the solute in the liquid phase, the content of solute rejected from the solid phase becomes to show a peak in front of the solidification interface.

The trace of this peak content of solute was already proposed as Eq. (3) by Tiller, et al. ${ }^{19)}$ and Grigorenko: ${ }^{201}$

$$
C_{\text {liq }}(x)=C_{\text {liq }}^{\circ}+C_{\text {liq }}^{\circ} \quad k \quad l-k\left[1-\exp \left(-\frac{k \cdot V \cdot x}{D_{\text {liq }}}\right)\right] \ldots
$$

where, $C_{1 \mathrm{iq}}^{\circ}$ : the initial content of the solute in the liquid phase

$k$ : the distribution coefficient

$D_{\text {liq }}$ : the diffusion coefficient of the solute in the liquid phase

$V$ : the rate of solidification

$x$ : the solidified distance.

As the solidification proceeds, the peak value increases gradually and attained to a constant value $C_{1 \mathrm{iq}}^{\circ} / k$ finally. The peak content of the solute depends on the distribution coefficient and becomes considerably higher than the initial content of the solute $C_{\text {liq }}^{\circ}$. Therefore, the condition for the stable presence of a bubble mentioned above $(=25.2 \mathrm{cc} / 100 \mathrm{~g}$ Fe $)$ would be obtained. Equation (4) is obtained from Eq. (3).

$$
x=-\frac{D_{\mathrm{iiq}}}{k V} \ln \left[\begin{array}{c}
C_{\mathrm{liq}}^{\circ}-k C_{\mathrm{iiq}}(x) \\
C_{\mathrm{liq}}^{\circ}(1-k)
\end{array}\right]
$$

By changing the values of $k$ and $C_{1 i q}^{\circ}$, the solidification distance $x$ which is necessary for $C_{1 \text { iq }}(x)$ to exceed the value of $25.2 \mathrm{cc} / 100 \mathrm{~g} \mathrm{Fe}$ was calculated, and the results obtained are shown in Fig. 6. In this calculation, $1 \times 10^{-3} \mathrm{~cm}^{2} / \mathrm{sec}$ is used as the value of the diffusion coefficient of hydrogen in molten iron, $D_{\text {liq. }}{ }^{21)}$ The rate of solidification $V$ is assumed to be $1 \mathrm{~cm} / \mathrm{sec}$ from the cooling curve shown in Fig. 2. In Fig. 6, the vertical axis represents the solidification distance $x$ which is necessary for the maximum content of dissolved hydrogen to exceed the value of $25.2 \mathrm{cc} / 100 \mathrm{~g} \mathrm{Fe}$, and the horizontal axis the distribution coefficient $k$. In the regions surrounded by the straight line corresponding to the equilibrium distribution coefficient 0.31 and the calculated curves showing the solidification distance $x$ necessary for the blowhole formation, a bubble can be sustained for a corresponding value of $C_{\text {iiq }}^{\circ}$. When $C_{1 \mathrm{iq}}^{\circ}$ is less than $7.82 \mathrm{cc} / 100 \mathrm{~g} \mathrm{Fe}$, the maximum content of dissolved hydrogen can not exceed the value of $25.2 \mathrm{cc} / 100 \mathrm{~g}$ $\mathrm{Fe}$ as is obvious from Eq. (4) and then bubbles can not be sustained.

In the case that $C_{\text {liq }}^{\circ}$ is equal to $9 \mathrm{cc} / 100 \mathrm{~g} \mathrm{Fe}$ (corresponding to the melting under a $5 \% \mathrm{H}_{2}-\mathrm{Ar}$ atmosphere at $2000^{\circ} \mathrm{C}$ ), bubbles can be sustained if the effective distribution coefficient is between 0.31 and 0.36. On the other hand, when the coefficient exceeds 0.36, no bubble can be sustained. According to the present results, blowholes are not observed in the specimen having this content of hydrogen. Therefore, the effective distribution coefficient must be more than 0.36. The similar estimation leads to the conclusion that the effective distribution coefficient must be about 0.52 under these experimental conditions, by taking account of the fact that the critical content of dissolved hydrogen for blowhole formation is $13 \mathrm{cc} / 100 \mathrm{~g} \mathrm{Fe}$. This estimated value is considerably close to the unity as compared with the equilibrium distribution coefficient 0.31 . It is well known that the distribution coefficient depends generally on the rate of solidification. As the rate of solidification is very rapid under these experimental conditions, it seems that this estimated value is reasonable.

Moreover, it is found from Fig. 6 that the least solidification distance which is necessary for the sustenance of a bubble is of the order of $100 \mu$. This conclusion supports the fact that blowholes originate from the points which are very close to the wall surface of solidified specimen.

Next, we deal the case that the rate of solidification is considerably slow as in the case of practical steel casting. As the effective distribution coefficient approachs to the equilibrium one, the critical content of dissolved hydrogen for blowhole formation must be considerably lower than $13 \mathrm{cc} / 100 \mathrm{~g} \mathrm{Fe}$ because of the slow rate of solidification. When the effective distribution coefficient is equal to the equilibrium one,

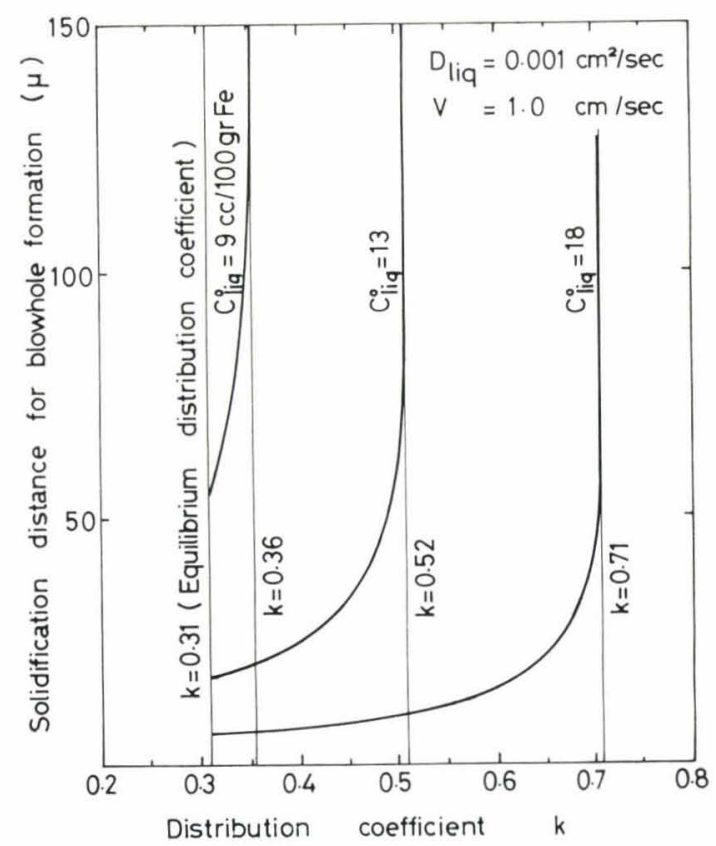

Fig. 6. Relationship between distribution coefficient and solidification distance for blowhole formation 
the critical content of dissolved hydrogen for blowhole formation is equal to $7.82 \mathrm{cc} / 100 \mathrm{~g} \mathrm{Fe}$. Accordingly, blowholes can not be formed in the specimen at any rate of solidification if the value is less than this content.

Since the results reported by Sykes, et al. and also by Barraclough quoted in the introduction are not concerned with pure iron, but high-alloy steels, the present results can not be directly compared with their results. But, it seems that their critical values may not be so different from the critical content of dissolved hydrogen estimated from the uniaxial planar solidification model, if these factors are taken into consideration.

\section{Conclusions}

The blowhole formation in the $\mathrm{Fe}-\mathrm{H}$ system during the period of solidification has been investigated.

The results obtained are summarized as follows:

Although the blowhole formation depends markedly on both the partial pressure of hydrogen and the temperature of the melt, a critical value for the blowhole formation is determined definitely in view of the content of dissolved hydrogen in the specimen. The value obtained was $13 \mathrm{cc} / 100 \mathrm{~g} \mathrm{Fe}$ under the experimental conditions adopted. In other words, when the content of dissolved hydrogen in molten iron exceeds this value, blowholes are formed.

So as to sustain a bubble in molten iron, the solubility of hydrogen in molten iron must be at least $25.2 \mathrm{cc} / 100 \mathrm{~g} \mathrm{Fe}$ which is the equilibrium value at the melting point of pure iron under one atmospheric pressure of hydrogen.

The obtained critical content of hydrogen, $13 \mathrm{cc} /$ $100 \mathrm{~g} \mathrm{Fe}$, is much lower than the value of $25.2 \mathrm{cc}$ $100 \mathrm{~g} \mathrm{Fe}$. When the concentration of hydrogen in front of the solidification interface is considered, the maximum content of hydrogen can exceed the value of $25.2 \mathrm{cc} / 100 \mathrm{~g} \mathrm{Fe}$. Therefore, blowholes can easily be formed in the specimen, even though the content of hydrogen in the bulk of molten iron has the lower value of $13 \mathrm{cc} / 100 \mathrm{~g} \mathrm{Fe}$. It is also shown that the critical content of dissolved hydrogen which is necessary for the blowhole formation and the change of the distribution coefficient from the equilibrium one depend on the rate of solidification.

\section{REFERENCES}

1) C. Sykes, H. H. Burton and C. C. Gegg: JISI, 156 (1947), 155

2) K. C. Barraclough: Murex Rev, 1 (1954), 305.

3) M. Uda, S. Ohno and T. Wada: J. Japan Welding Soc., 38 (1969), 72

4) M. Uda and S. Ohno: J. Japan Welding Soc., 41 (1972), 12.

5) H. Sekiguchi and I. Masumoto: J. Japan Welding Soc., 27 (1958), 331 .

6) I. Masumoto: J.Japan Welding Soc., 29 (1960), 956.

7) M. Uda and S. Ohno: J. Japan Welding Soc., 42 (1973), 225.

8) M. Uda and S. Ohno: Japan Light Metal Welding, (1973), No. $125,215$.

9) M. Uda and R. D. Pehlke: AFS Cast Metals Research Journal, (1974), March, 30.

10) M. Uda and R. D. Pehlke: Report of National Research Inst. Metals 18 (1975), 39.

11) H. Wada, K. Gunji and T. Wada: J. Japan Inst. Metals, 32 (1968), 831.

12) M. Weinstein and J. F. Elliott: Trans. Met. Soc. ALME, 227 (1963), 382.

13) W. Geller and Tak-Ho Sun: Arch. Eisenhüttenw., 21 (1950), 423.

14) F. Matsuda: Welding Metallurgy, Nikkan Kogyo Shinbun, (1972), 79.

15) L. D. Lucas: Compt. Rend., 250 (1960), 1850.

16) B. C. Allen and W. D. Kingery: Trans. Met. Soc. AIME, 215 (1959), 30.

17) B. Chalmers: Principles of Solidification, John Wiley \& Sons Inc., New York, (1964), 134.

18) K. Niwa: Tetsu-to-Hagané, 53 (1967), 47.

19) W. A. Tiller, K. A. Jackson, J. W. Rutter and B. Chalmers: Acta Met., 1 (1953), 428.

20) G. M. Grigorenko: Auto. Weld. LSSR, 23 (1970), No. 10, 13.

21) N. M. El-Tayeb and N. A. D. Parlee: Trans. Met. Soc. AIME, 239 (1967), 1345. 